\title{
How small can you go? A 2.5 -kg infant with pulmonary atresia and coronary atresia bridged to cardiac transplantation with a paracorporeal-continuous flow ventricular assist device
}

Chet R. Villa, MD, Angela Lorts, MD, Kyle W. Riggs, MD, Jeffrey Alten, MD, and David L. Morales, MD, Cincinnati, Ohio

\footnotetext{
From The Heart Institute, Cincinnati Children's Hospital Medical Center, Cincinnati, Ohio.

Disclosures: A.L. has received grants from Abbott and Medtronic and training fees from SynCardia and Berlin Heart. D.L.M. has served as consultant, instructor, medical advisory board member, or principal investigator for Berlin Heart, SynCardia, CorMatrix, and Abbott Medical. All other authors have nothing to disclose with regard to commercial support.

Received for publication July 12, 2018; revisions received Aug 28, 2018; accepted for publication Sept 9, 2018; available ahead of print June 10, 2019.

Address for reprints: Chet R. Villa, MD, 3333 Burnet Ave, MLC 2003, Cincinnati, OH 45229 (E-mail: Chet. villa@cchm.org).

J Thorac Cardiovasc Surg 2019;158:e67-9

$0022-5223 / \$ 36.00$

Copyright (C 2018 by The American Association for Thoracic Surgery

https://doi.org/10.1016/j.jtcvs.2018.09.027
}

The patient was a $2.5-\mathrm{kg}$ male neonate with prenatally diagnosed pulmonary atresia, dysplastic tricuspid valve, right coronary atresia, and severe left anterior descending coronary artery dilation. Cardiac catheterization revealed right coronary ostial atresia with retrograde filling from the left anterior descending coronary artery and fistulas with bidirectional flow between the right ventricle and the left anterior descending coronary artery. The patient was listed for heart transplant and maintained on prostaglandin. He began having periods of severe agitation and myocardial ischemia, resulting in low cardiac output and decreased systemic oxygen delivery requiring rescue epinephrine.

Because of his tenuous status, the patient underwent 3.5-mm Blalock-Taussig shunt, atrial septectomy, and placement of a CentriMag (Abbott, Chicago, Ill) ventricular assist device (VAD). The right atrial appendage was cannulated with a Medtronic 14F right-angle metal tip venous cannula (Medtronic, Minneapolis, Minn). The aorta was cannulated by sewing a 4-mm chimney graft to the side of the aorta and placing a Sorin (12F 135 degree aortic cannula LivaNova, PLC, London, UK) into the graft so that the tip barely entered the aorta, to avoid kinking of the graft during closure of the sternum (Figure 1). The cannulas were tunneled thru the skin and connected to Medtronic Balance coated 0.25-inch tubing with 0.25-inch connectors. The 0.25 -inch tubing was then connected to the CentriMag with 0.25-inch to 0.375-inch tapered Medtronic Balance coated tubing, and the chest was closed without need for blood products in the postoperative course. The initial VAD speed was $2400 \mathrm{rpm}$ with cardiac index of $4 \mathrm{~L} / \mathrm{min} / \mathrm{m}^{2}$. The speed was subsequently up titrated to

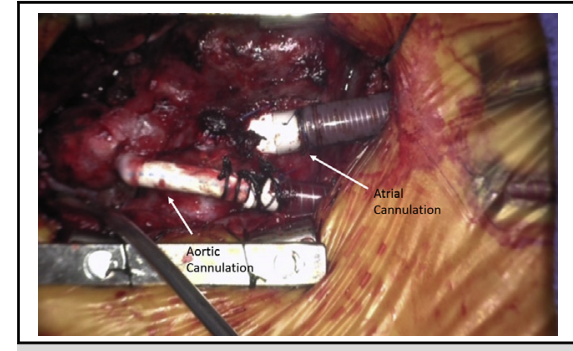

Intraoperative picture depicting atrial and aortic cannulation.

\section{Central Message}

Novel paracorporeal ventricular assist device support strategy and modified patient selection make bridge to transplant of small, shuntdependent infants possible.

See Commentary on page e71.

$2700 \mathrm{rpm}$ during the first 24 hours to maintain a cardiac index of 5.5 to $6 \mathrm{~L} / \mathrm{min} / \mathrm{m}^{2}$, with improvement in near-infrared spectroscopy, venous oximetry, lactate, and end-organ function (Figure 2). The patient was quickly weaned from intravenous vasoactive medications. The systemic ventricle continued to eject (pulse pressures of approximately $10 \mathrm{~mm} \mathrm{Hg}$ ), despite high VAD flows and $\mathrm{PO}_{2}$ in the low 40s.

The patient was extubated on postoperative day (POD) 7 and remained so throughout the 137 days of VAD

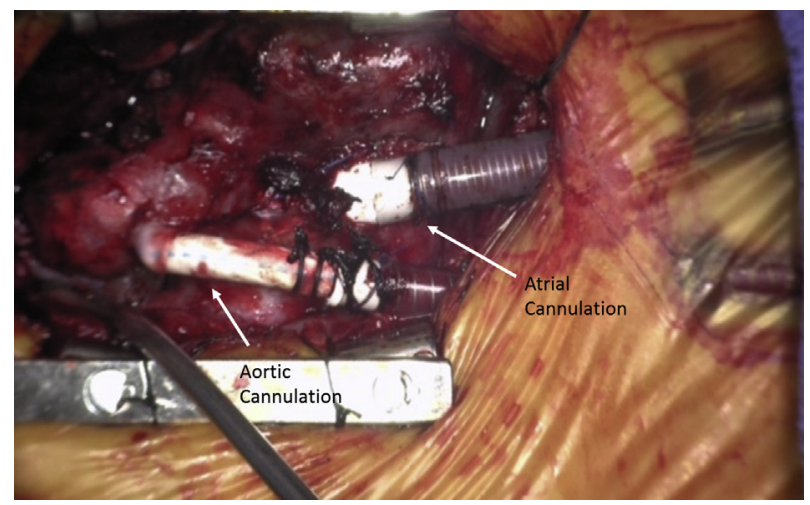

FIGURE 1. Intraoperative picture depicting atrial and aortic cannulation. 

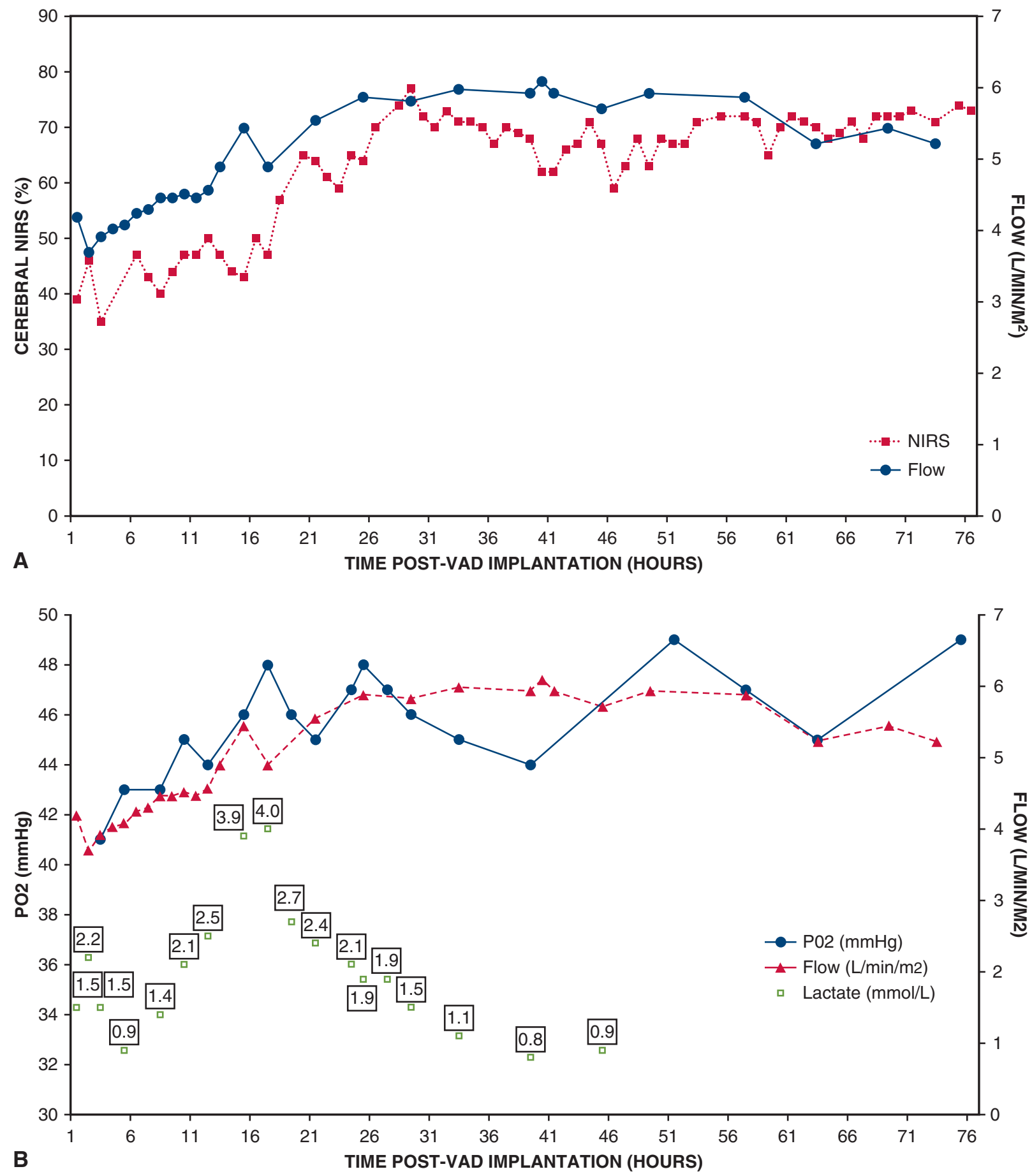

FIGURE 2. A, Temporal trends in ventricular assist device $(V A D)$ flow and near-infrared spectroscopy (NIRS) values. B, Temporal trends in ventricular assist device flow, $\mathrm{Po}_{2}$, and lactate values.

support. He tolerated full enteral feedings with good growth $(31 \mathrm{~g} / \mathrm{d})$. The patient was anticoagulated with bivalirudin and aspirin (initiated POD 20 and up titrated to $8 \mathrm{mg} / \mathrm{kg}$ daily). He had no hemolytic, thrombotic, bleeding, infectious, or neurologic complications. $\mathrm{He}$ had no problems with his cannula exit sites. One circuit change out was performed on POD 13 because of clot formation within the tubing, but no clot was seen in the device. The lactate dehydrogenase ranged from 200 to $350 \mathrm{U} / \mathrm{L}$. 
The effectiveness of this support strategy was reflected in the early transplant course, during which the patient's end-organ function was preserved (maximum creatinine level of $0.39 \mathrm{mg} / \mathrm{dL}$ ). His hospital discharge was delayed until POD 42 because of nosocomial human metapneumovirus infection requiring reintubation. The patient otherwise has done well as of 3 months after the transplant.

\section{DISCUSSION}

The VAD outcomes of small children $(<5 \mathrm{~kg})$ with congenital heart disease and single-ventricle physiology lag far behind the generally good survival for larger patients and those with 2-ventricle anatomy. ${ }^{1}$ Because of the history of poor outcomes when using Berlin EXCOR VADs (Berlin Heart, Inc, The Woodlands, Tex) to support small, infants with single-ventricle physiology, an alternate support strategy of using paracorporeal, continuous-flow VADs has emerged. ${ }^{2}$ The use of paracorporeal continuous-flow devices may be better suited for the effective management of rapid changes in preload, changes in ventilationperfusion ratio, and the volume load associated with shunt physiology inherent in single-ventricle physiology.

There are anecdotal and mathematical modeling data suggesting that the use of paracorporeal, continuous-flow VADs with higher than typical rotational speed and flow goals may be a more successful strategy for supporting infants with single-ventricle physiology. ${ }^{3}$ On the basis of this information, as well as our own experience with other patients with congenital heart disease, we anticipated greater device output needs than typical. A CentriMag device was therefore chosen rather than a PediMag device (Abbott). The patient's course confirmed our suspicions, because the patient continued to have systemic ventricular ejection and a pulse pressure despite VAD flows of $6 \mathrm{~L} / \mathrm{min} / \mathrm{m}^{2}$. Although the cardiac output that the patient ultimately required might have been achievable with the PediMag device, it is difficult to know these needs in advance. Given these considerations and the potential for significant somatic growth early in life, we would advocate the use of larger device as long as greater than minimum flow rates are expected.

Most importantly, we believe that early initiation of VAD therapy played a significant role in the positive outcome of this patient. Historically, VAD support has not been initiated in small patients or those with shunted singleventricle physiology because of the perception of a poor outcome-often waiting until failed palliation, end-organ injury, or unstable hemodynamics to provide this support, which only ensures the predicted poor outcome. ${ }^{4,5}$

In conclusion, we report successful VAD support and bridge to transplantation of a $2.5-\mathrm{kg}$ patient with shunted single-ventricle physiology. Our clinical experience suggests that VAD support is possible in very small infants with shunted single-ventricle physiology with good patient selection, device choice, and device management that takes into account the cardiac output needs inherent in the shunted physiology.

\section{References}

1. Almond CS, Morales DL, Blackstone EH, Turrentine MW, Imamura M, Massicotte MP, et al. Berlin Heart EXCOR pediatric ventricular assist device for bridge to heart transplantation in US children. Circulation. 2013;127: 1702-11.

2. Lorts A, Eghtesady P, Mehegan M, Adachi I, Villa C, Davies R, et al. Outcomes of children supported with devices labeled as "temporary" or short term: a report from the Pediatric Interagency Registry for Mechanical Circulatory Support. J Heart Lung Transplant. 2018;37:54-60.

3. Schmidt T, Rosenthal D, Reinhartz O, Riemer K, He F, Hsia TY, et al, Modeling of Congenital Hearts Alliance (MOCHA)+ Investigators. Superior performance of continuous over pulsatile flow ventricular assist devices in the single ventricle circulation: a computational study. J Biomech. 2017;52:48-54.

4. Morales DLS, Zafar F, Almond CS, Canter C, Fynn-Thompson F, Conway J, et al. Berlin Heart EXCOR use in patients with congenital heart disease. J Heart Lung Transplant. 2017;36:1209-16.

5. Weinstein S, Bello R, Pizarro C, Fynn-Thompson F, Kirklin J, Guleserian K, et al The use of the Berlin Heart EXCOR in patients with functional single ventricle. J Thorac Cardiovasc Surg. 2014;147:697-704; discussion 704-5. 